\title{
Article
}

\section{Guidance on Implementing Renewable Energy Systems in Australian Homes}

\author{
Peter Horan (1), Mark B. Luther *(i) and Hong Xian Li
}

Citation: Horan, P.; Luther, M.B.; Li, H.X. Guidance on Implementing Renewable Energy Systems in Australian Homes. Energies 2021, 14, 2666. https://doi.org/10.3390/en 14092666

Academic Editors:

George Kosmadakis and Carlo Renno

Received: 24 March 2021

Accepted: 29 April 2021

Published: 6 May 2021

Publisher's Note: MDPI stays neutral with regard to jurisdictional claims in published maps and institutional affiliations.

Copyright: (c) 2021 by the authors. Licensee MDPI, Basel, Switzerland. This article is an open access article distributed under the terms and conditions of the Creative Commons Attribution (CC BY) license (https:/ / creativecommons.org/licenses/by/ $4.0 /)$.
School of Architecture and Built Environment, Deakin University, Geelong, VIC 3220, Australia; peter@deakin.edu.au (P.H.); hong.li@deakin.edu.au (H.X.L.)

* Correspondence: luther@deakin.edu.au

\begin{abstract}
The purpose of this paper is to examine several real house cases as renewable energy resources are installed. It is an empirical study, based on first principles applied to measured data. In the first case presented, a PV solar system has been installed and a hybrid vehicle purchased. Battery storage is being considered. Smart Meter data (provided in Victoria, Australia) measures the electrical energy flowing to and from the grid in each half hour. Missing is the story about what the house is generating and what its energy requirements are through each half hour interval. We apply actual (on site) solar PV data to this study, resolving the unknown energy flows. Analysing energy flow has revealed that there are five fundamental quantities which determine performance, namely energy load, energy import, energy harvesting, energy export and energy storage. As a function of PV size these quantities depend on four parameters, easily derivable from the Smart Meter data, namely the house load, the night-time house load (no PV generation), the rating of the solar PV system and the tariffs charged. This reveals most of the information for providing advice on PV array size and whether to install a battery. An important discovery is that a battery, no matter what size, needs a PV system large enough to charge it during the winter months. The analysis is extended to two more houses located within $5 \mathrm{~km}$ for which detailed solar data is unavailable.
\end{abstract}

Keywords: solar PV; battery; costs; $\mathrm{CO}_{2}$ emissions; electric vehicle

\section{Introduction}

The application of renewable energy systems to Australian houses is not new, yet, it is doubtful that many owners could tell you why their selections of size of solar PV, batteries, solar hot water or electric vehicles were made. In fact, most residents have blindly left the decision making to others without any real economic or environmental understanding of what the combination of renewable energy systems implies for themselves as well as for the global environment. This paper is about a journey taken to convert an existing house into one using renewable energy. Furthermore, it is about discoveries and achievements through several stages of conversion from grid dependent to self-generated energy, as follows:

1. A house and car (petrol fuelled) with no renewable energy except a solar gas boosted water heater;

2. A house with a $3 \mathrm{~kW}$ Solar PV system and a plug-in hybrid (battery/petrol) car; and 3. Given the above, is a battery (and if so, what size) a good investment?

In fact, the above systems are those contemplated by many homeowners and system designers when considering what to include in a system using renewable energy. There is little guidance for the layman about integrating technologies as to what system sizes are recommended, or in fact are reasonable, for a particular homeowner's energy use and which considers their patterns of use. Guidance that is available from system installers tends to be derived in an opaque manner.

This paper presents a method readily available to the homeowner for the analysis of electrical energy consumption which predicts performance when such technologies are 
installed in an existing household. While the method is applied here, at first, to a specific household, it is not limited to this case and can be expanded to households elsewhere. Two more cases are analysed, one with a solar PV system that has a high feed-in tariff, and another household without any solar. This demonstrates a way of arriving at informed decisions for the selection and sizing of renewable energy products and implementations that are justified by data.

Underlying this, almost all Victorian households are monitored by "Smart Meters" which record electrical energy, both imported and exported, every half hour. In the absence of household electricity generation, this reveals a homeowner's distinctive patterns of electrical energy use. Unfortunately, if a solar PV system is installed, it does not reveal what happens "behind the meter", namely, the solar PV harvest and its contribution to the house load. For a complete picture, data from the PV system is required. However, even in the absence of detailed data from the solar PV system, Smart Meter data also provides the information to size a PV system, or alternatively extend it, and to determine whether energy diversion to a battery or thermal storage is viable. It may even assist at revisiting the existing heating and/or cooling system(s) installed as well as its fuel source for conditioning.

\section{A Review of Current Work}

Solar-powered homes are receiving increasing attention worldwide as a means of using renewable energy to reduce fossil fuel consumption and the environmental burden of residential buildings [1-3]. In Australia, private solar photovoltaic installations have been growing at a significant rate, both in capacity, more than doubling since 2009, and in number [4]. That paper reviewed the residential solar PV policy between 2001 and 2012 in Australia and identified that more than $2300 \mathrm{MWp}$ of residential PV were installed during that period as one of the results of policy incentives [3].

Feed-in Tariffs (FiTs) as well as significant rebate incentives, have been the primary driving force for the growth of solar PV homes in the last decade; however, FiTs continue to change over time and from state to state in Australia, ranging between AUD 0.66/kWh and AUD 0.05/kWh [3]. Apart from the politics, the environment of supplier tariffs and plans for grid electricity, especially when they involve solar PV, is complex [5].

Nicholls et al. [6] conducted comprehensive lifecycle economic and environmental analysis for rooftop PVs in Australia and found that the cost payback time ranges from 11 to more than 25 years in Australia. With the current rebate to homeowners, the dramatic fall in PV system costs and the increase in electrical costs (doubling in 10 years) this payback has decreased significantly with anecdotal 6-7 years payback [3]. More recent analyses for some homeowners indicates that paybacks of even 4 years are possible.

It has been reported recently that the growth of battery installations is on an exponential rise [7]; indeed, in 2019, Australians installed almost 23,000 home battery systems with a capacity of $233 \mathrm{MWh}$ [8]. When considering the application of batteries in households, the relations between the two parties, the consumer and the distribution network operators, need to be considered. Each party is affected differently. Increasing demand on the low voltage network due to changes in consumer behaviour will force network operators to change the way in which they manage and reinforce the network [9]. Ren et al. [10] have modelled the impact of PV battery systems on energy consumption and electricity bills under various tariffs in several Australian cities. No doubt, there are advantages for the distributor when the electrical feed-in is time-of-day regulated in order to smooth the output gains to the network. Both parties prosper when government develops a feed-in tariff incentive for PV systems with battery storage that can provide this balance [3].

The intermittent nature of solar PV output and the mismatch between customersited energy load profiles suggests that battery storage may be a means to maximise savings [11-13]. Figure 1 is an example of such a period of mismatch for the first house investigated. Through battery storage systems the variable output of PV to the grid is minimised and anticipates better control [3,11,14]. 


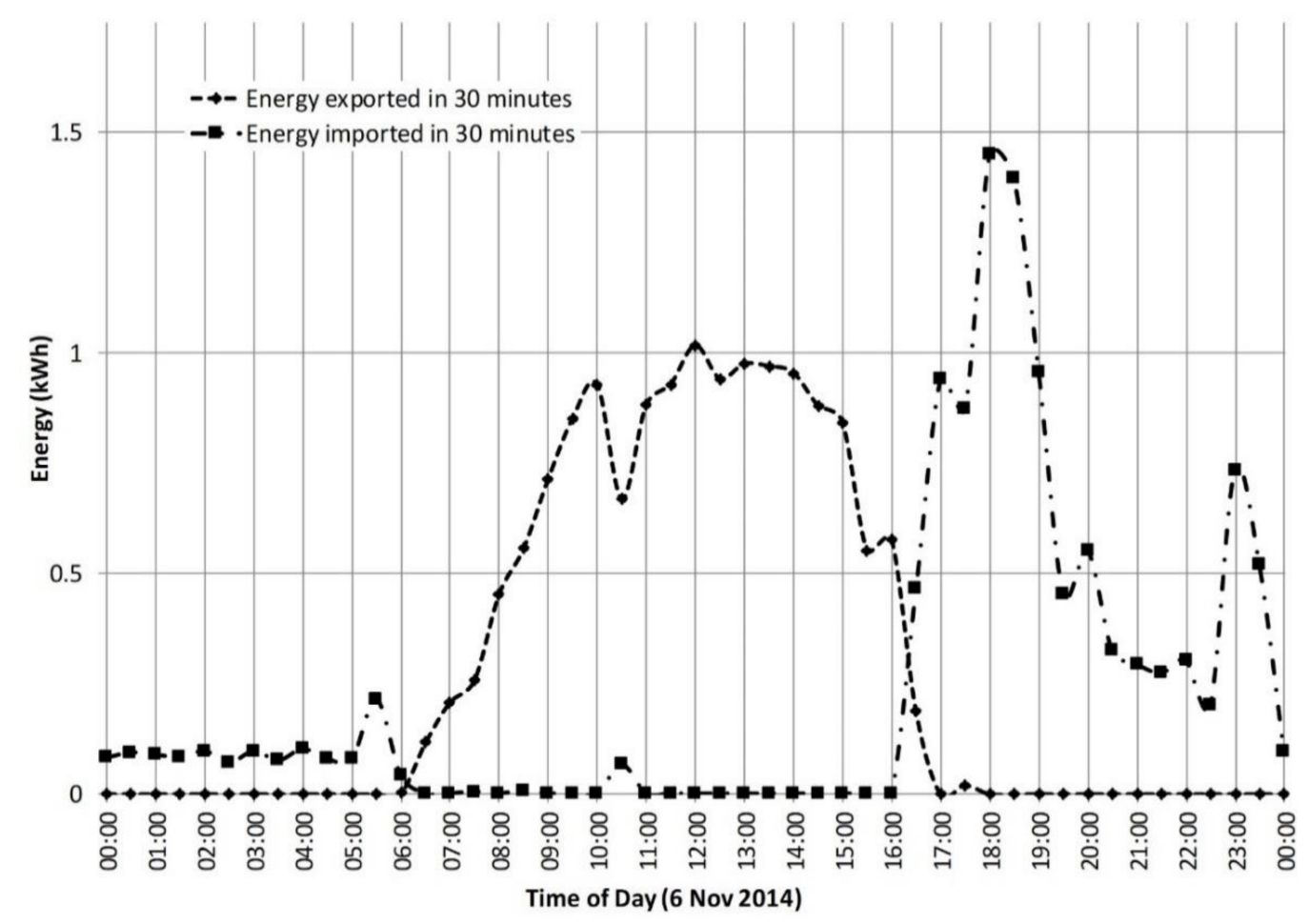

Figure 1. The mismatch of exported and imported energy.

Hassan et al. [11] provides such a circumstance where real data from a solar PV home is used to study by simulation the benefit of battery storage over a $30 \mathrm{~min}$ interval dataset for a full year. However, it is not clear whether the data came from individual homes or is an average of multiple projects. As reported in [15], a feed-in-tariff scheme that favours the installation of battery storage to maximise self-consumption is already in place in Germany. There is a growing need for affordable decentralised energy storage and the market is expected to grow rapidly.

Two different methods are available for energy storage in residential buildings, including onsite battery storage and through an electric vehicle (EV). Ren et al. [10] have analysed the impacts of integrated PV battery systems, including net present value (NPV) and peak demand for various tariff scenarios in several Australian cities for the studied cases. Horan and Luther [14] monitored and analysed the energy performance of an EV-integrated solar home and compared the actual energy performance of the home before and after the solar PV and EV were integrated.

Forrest et al. [16] compared the impacts of immediate charging, smart charging, and vehicle-to-grid charging on the scale of infrastructure required to meet renewable utilisation targets, and highlighted the importance of intelligent plug-in electric vehicle charging. Sarabi et al. [17] explored the potential of plug-in electric vehicles for vehicle to grid charging, based on statistical data; this research provides a full picture for the utilisation of electric vehicles.

Sizing battery storage for grid connected residential solar PV applications has been studied extensively. Research conducted on optimising battery sizing for residential projects is relevant and apparent [11,13,18-20]. Most of the existing research deals with the prediction of energy generation, its time-of-use and load calculation. Even the computation of available solar energy harvested by a PV system of a particular size is considered.

While some work uses existing 30 minute interval data to build an optimal model, the data is often not directly used to calculate and anticipate load time-of-use [21]. Relevant to the work presented here, that paper presents algorithms for determining optimal battery sizing, for a particular PV array and based upon time-of-use. It considers the dynamic use of collected energy, periods of mismatch as well as missed opportunities for storage. 
Battery size is an important factor for onsite energy storage in solar homes. As there is a considerable difference between the tariffs to supply electricity from the grid and to feed electricity into the grid, this is an important topic for solar homes. There are several estimating tools for solar homes regarding solar PV sizing and onsite battery sizing. The calculator [22] offers a method to calculate solar PV size based on annual electricity consumption and solar hours per day at a specific location to achieve net zero electrical emissions. Solar Calculator [23] uses a house postal code, average bill, roof design, solar system size, and battery size, to conduct a comprehensive analysis. Aichhorn et al. [19] highlighted the benefits of using energy storage for residential buildings and conducted the economic analysis to determine battery size based on simulation. Weniger et al. [18] analysed residential PV battery systems to examine the system sizing. Simulation and sensitivity analysis were conducted to identify appropriate system configurations. This research concluded that PV systems with batteries would not only be profitable but also the most economical solution from the long-term perspectives. Hassan et al. [11] studied the techno-economic benefits of battery storage coupled to photovoltaic (PV) generation system; in this research, simulation, optimisation, and sensitivity analysis are conducted to analyse the benefits considering different electricity tariffs and battery storage. In addition to the growth in popularity of solar homes, another concern is the impact of solar homes on the electricity grid. Agnew and Dargusch [24] explored the impact of residential solar and storage on the electrical distribution network.

Given the fact that there exists a considerable price difference between supplying electricity from the grid and feeding electricity into the grid, local energy storage with appropriate battery size is an emerging topic for solar homes. While metering data provides valuable information for deciding on energy storage, the research on using metering data, collected in the absence of energy storage, has not been extensively conducted. In addressing this identified research gap, this paper presents research on using Smart Meter data, to determine the impact of energy storage on cost.

Another significant aspect of the literature is in regard to battery type, recharging cycles, deterioration and lifespan $[9,12,17,19]$. The affordability of battery storage critically depends on capital cost and life span. Estimating battery life span and optimising battery management to increase life span is difficult [21]. Furthermore, determining the optimal size of a battery according to its optimal daily use is a challenging decision. All the factors as well as their time-of-occurrence need to be considered: charging and discharging, depth-of-discharge, minimum and maximum cycling limits, battery currents and battery temperature. In [21], Muenzel et al. have studied Li-ion battery cycling and discovered that cycles that fully charge and discharge them degrades these batteries more than small more frequent cycles.

Our work is distinct because it is based on an existing PV system with actual generation and user patterns for a house with a hybrid EV rather than averaged or modelled data. It utilises a year of Smart Meter data, solar PV data and EV charging data. The Smart Meter, installed by the electricity provider, records the quantity of electricity supplied from the grid and fed into the grid at half-hourly intervals. Applying first principles to actual data is worthwhile because averages and models may hide unexpected behaviour. For example, in summer, the maximum and minimum daily energy harvested was $21.2 \mathrm{kWh}$ on 11 December 2018 and $5 \mathrm{kWh}$ two days later. In winter 2019, the maximum was $9.17 \mathrm{kWh}$ on 7 May and the minimum was $2.17 \mathrm{kWh}$ on 10 May.

The main assumptions in this analysis are that the battery is charged only from the solar PV system and not from the grid and that energy is drawn from the battery before drawing energy from the grid [14].

The use of Smart Meters in grid connected systems is the norm for most households in the state of Victoria, Australia. Smart Meter data can be used to determine the effects of Solar PV system size and battery storage on a particular household according to its user patterns. As the immediate past two years of Smart Meter data can be downloaded from 
the network supplier, our method can be applied to any household considering adding battery storage [14].

In addition to Smart Meter data, solar data is required to calculate the impact of PV system size. The resulting analysis shows the effect of both PV system size and battery size on a particular household and its energy use and may suggest alternatives to manage excess electricity and other means of energy storage.

The question of whether to invest in solar PV or batteries or some mix, depends on one's aims. Many domestic installers aim to reduce their carbon footprint, so a PV system which achieves a "net zero energy" goal may be chosen. Other installers aim to reduce or eliminate the recurrent cost of energy, in which case a larger PV system would be the choice. Some users may wish to shift the time of peak load, provide solar power throughout the night or exploit off-peak grid supply rates, so batteries would be required. In country areas, some may aim to work "off-grid", so a still larger PV system and battery installation would be the choice.

In this paper, based on grid-connected houses, we investigate the relationship between imported and exported grid energy, solar PV system size, battery size, house load and night-time load, and energy costs based on a simple flat tariff. When a house does not have solar energy, or a record of solar energy is not available, we used solar data from a nearby house as a proxy. This study shows how the various elements of the system interact to map out the landscape of domestic solar PV systems in an understandable way for the homeowner.

It is not the purpose of this paper to replace the expert advice available from qualified installers, but rather to enable meaningful discussions between parties. We ignored, for example, energy losses in inverters and cables and round-trip losses in batteries. Furthermore, we did not account for variable tariffs and we assumed that batteries charge only from the solar PV system and feed only the house. Charging batteries from and discharging them to the grid is not considered. Nevertheless, the analyses done reveal how the parts of an installation interact and relate to each other in an understandable way.

\section{The Move towards Going Solar}

When first considering solar PV, finding uses for solar energy when it exceeds the load, rather than passively exporting it to the grid, was also considered. The outcome was a decision to purchase a plug-in hybrid electrical vehicle as well as installing a $3 \mathrm{~kW}$ solar photovoltaic (PV) system. The additional load of charging the vehicle, being compensated by the solar harvest, did not affect the annual grid demand or cost of electricity. As a result, comparing the years before and after installation, about $4 \mathrm{MWh}$ of electrical energy was generated and AUD 1300 saved by reducing petrol purchases by over $80 \%$. Overall, estimated $\mathrm{CO}_{2}$ emissions from the household were reduced by $54 \%$ [5].

For this case, we present an analysis of data relating to energy use within the house. In Victoria, Australia, electrical data consumption is available from the provider for the entire year for each half-hour using Smart Meters, which were installed in 2013. Data from the vehicle was recorded before and after each charging event and when the car was refuelled. As a result, the data was available to do a before and after analysis of energy generation and consumption. Additional instrumentation records the energy generation from the solar PV and charging energy of the vehicle [5].

After installing solar PV and a hybrid car, the next questions to consider are the impact of the PV system size and whether a battery for energy storage is a viable option. Here we quantify the relationships between system size and harvested solar energy and energy imported from and exported to the grid. We also estimate how energy costs fall as system size grows as we explore the effect of introducing batteries of various size into the system. Again, this was accomplished using Smart Meter data from the power supply company and solar data recorded from the PV system controller. The conclusion reached is that increasing PV system size is much more effective than installing batteries, (at the moment) both in terms of energy and cost [14]. 
Finally, based on the work performed thus far, we consider its application to other households: one, a household that has a solar PV system; and one that has no solar PV. Based on the Smart Meter data from each house, and solar data gathered at the first household, we conclude that suitable guidance can be provided to individual households for solar PV and battery sizing based upon their energy usage patterns.

\subsection{Working with Smart Meter and Solar Data}

Energy related to a house are the grid energy and, if a PV system is installed, solar energy. Therefore, in a time interval, $n$ :

$$
E_{H}(n)=E_{G}(n)+E_{S}(n)
$$

where:

- $E_{H}$ is the house load;

- $E_{G}$ is the grid energy, positive if imported into the house, and negative if exported; and

- $E_{S}$ is the harvested solar energy.

For billing purposes, Smart Meter data separates imported and exported energy and records them separately:

$$
E_{G}(n)=E_{I}(n)-E_{E}(n)
$$

where:

- $E_{I}$ is the energy imported from the grid; and

- $E_{E}$ is the energy exported to the grid.

In terms of Smart Meter data, the house load is:

$$
E_{H}(n)=E_{I}(n)-E_{E}(n)+E_{S}(n)
$$

Note that the imported energy and exported energy flow on the same wire, and at any instant, either the exported energy is zero when energy is being imported from the grid, or else the imported energy is zero when energy is being exported. Furthermore, in the absence of a solar PV system, there is no exported energy so that $E_{S}$ and $E_{E}$ are zero. Smart Meter data totalise energy in a particular half hour interval, so that, when the solar harvest and load are almost equal, grid energy can be imported for some subintervals and exported for the remainder. Therefore, the Smart Meter data can show energy both being imported and exported in the whole 30 minute interval.

\subsection{The House Prior to Any Renewable Energy Installations}

The original house was built in 2005 to achieve good summer and winter performance by using double glazing, insulation in ceiling, walls and floor, eaves over windows and external blinds. As it was built on fill (of a former gully), a lightweight timber and brick veneer building supported by piles engaged with footings and brick piers was used. Therefore, the building incorporated no major concrete slab to provide thermal storage. A gas-boosted solar hot water system was the only renewable energy technology incorporated.

The energy used by the house and car for 12 months prior to installing renewable energy is listed in Table 1 . This includes the energy used by the car as well, anticipating the installation of the hybrid electric vehicle [5]. 
Table 1. Energy use prior to installing solar panels (May 2013-April 2014).

\begin{tabular}{cccc}
\hline & & Energy in & Payment \\
\hline House & Electricity Grid & $3806 \mathrm{kWh}$ & AUD 1524.26 \\
& Gas & $3842 \mathrm{kWh}$ & AUD 479.58 \\
& Solar HWS & Up to $1694 \mathrm{kWh}$ & \\
& & available $[23]$ & \\
Car $(9696 \mathrm{~km})$ & Petrol & $10,685 \mathrm{kWh}$ & AUD 1679.03 \\
& & $(1113 \mathrm{~L} \times 9.6 \mathrm{kWh} / \mathrm{L})$ & AUD 3682.87 \\
\hline
\end{tabular}

\subsubsection{The House with Solar PV and a Hybrid Car}

This work began with considerations arising when contemplating a solar PV system. In particular, there would be times when energy harvested by the system would exceed the house load and would be exported. As the feed-in tariff was low, the question to be asked was whether there would be uses for this excess harvested energy which would be of benefit, either monetarily or environmentally? Could the imported energy be reduced by the excess of another period? Water heating was ruled out, because a gas-boosted solar hot water system was already installed; air conditioning was deemed unnecessary because of the good house performance; and battery storage was too expensive. However, replacing a vehicle was necessary at the time and a plug-in hybrid vehicle was purchased.

A $3.0 \mathrm{~kW}$ photovoltaic system was switched on 1 July 2014 and harvested 3.94 MWh of energy to 30 June 2015 or $10.8 \mathrm{kWh} /$ day. The system has 12 solar panels rated at $250 \mathrm{~W}$ each with a microinverter generating $240 \mathrm{~V}$ AC power, which reports to the system controller. (In hindsight, due to the experimental nature of this household case, it was a wise decision to select panels with independent microinverters. This means that each panel converts its DC power into $240 \mathrm{AC}$, allowing for easy future expansion of the solar array without the need to purchase a new stand-alone inverter). The total active area is $20 \mathrm{~m}^{2}$, so the harvested power density averages $22.8 \mathrm{~W} / \mathrm{m}^{2}$ over a year. (The power density of $22.8 \mathrm{~W} / \mathrm{m}^{2}$ is found by averaging over a whole year including night-time when the solar power is zero). This figure is $1.7 \%$ of the solar constant of about $1350 \mathrm{~W} / \mathrm{m}^{2}$ [25]. It is also $12 \%$ of the annual averaged direct normal radiation of $193 \mathrm{~W} / \mathrm{m}^{2}$ as reported, for example, in [26]. Some of the difference is caused by the innate efficiency limits of silicon solar panels and the angle of installation, flat on the roof of about $5^{\circ}$ incline. The power density is consistent with (of the same order as) that reported for the United Kingdom in [27].

The annual energy flows to and from the house and hybrid car are listed in Table 2 and illustrated in Figure 2. Costs are also listed. Energy from five sources, the grid, the solar panels, the gas supply, petrol supply and the solar hot water service, flows to the house and the car. The incoming electrical energy of almost $8 \mathrm{MWh}$ is shared almost equally between the grid and the solar harvest. The house takes about $4 \mathrm{MWh}$, the car, 1.9 MWh, and the balance of about $2 \mathrm{MWh}$ is in excess of demand from time to time during the day and is exported. 
Table 2. Energy use and costs with solar panels and plug-in hybrid vehicle.

\begin{tabular}{|c|c|c|c|c|c|}
\hline & & $\begin{array}{c}\text { Energy in } \\
(\mathrm{kWh})\end{array}$ & Payments & $\begin{array}{c}\text { Energy out } \\
\text { (kWh) }\end{array}$ & Receipts \\
\hline \multirow[t]{5}{*}{ House } & Electricity grid & 4017 & \multirow[t]{2}{*}{1641.98} & 2047 & \multirow[t]{2}{*}{$\begin{array}{c}\text { AUD } \\
145.20\end{array}$} \\
\hline & Solar panels & 3941 & & \multirow[b]{2}{*}{3573} & \\
\hline & Gas & 3573 & \multirow[t]{2}{*}{$\begin{array}{c}\text { AUD } \\
544.56\end{array}$} & & \\
\hline & Solar HWS & \multirow[t]{2}{*}{1694} & & \multirow{2}{*}{$\begin{array}{l}1694 \\
4019\end{array}$} & \\
\hline & Electricity use & & & & \\
\hline Car & Petrol (191 L) & \multirow[t]{2}{*}{1833} & $\begin{array}{c}\text { AUD } \\
250.90\end{array}$ & 1833 & \\
\hline$(10,519 \mathrm{~km})$ & Electricity & & & \multirow[t]{3}{*}{1892} & \\
\hline & & \multirow{4}{*}{15,058} & AUD & & AUD \\
\hline & lotal & & 2437.44 & & 145.20 \\
\hline & Total energy $(\mathrm{kWh})$ & & & \multirow[t]{2}{*}{15,058} & \\
\hline & Net running cost & & $\begin{array}{c}\text { AUD } \\
2292.24\end{array}$ & & \\
\hline
\end{tabular}

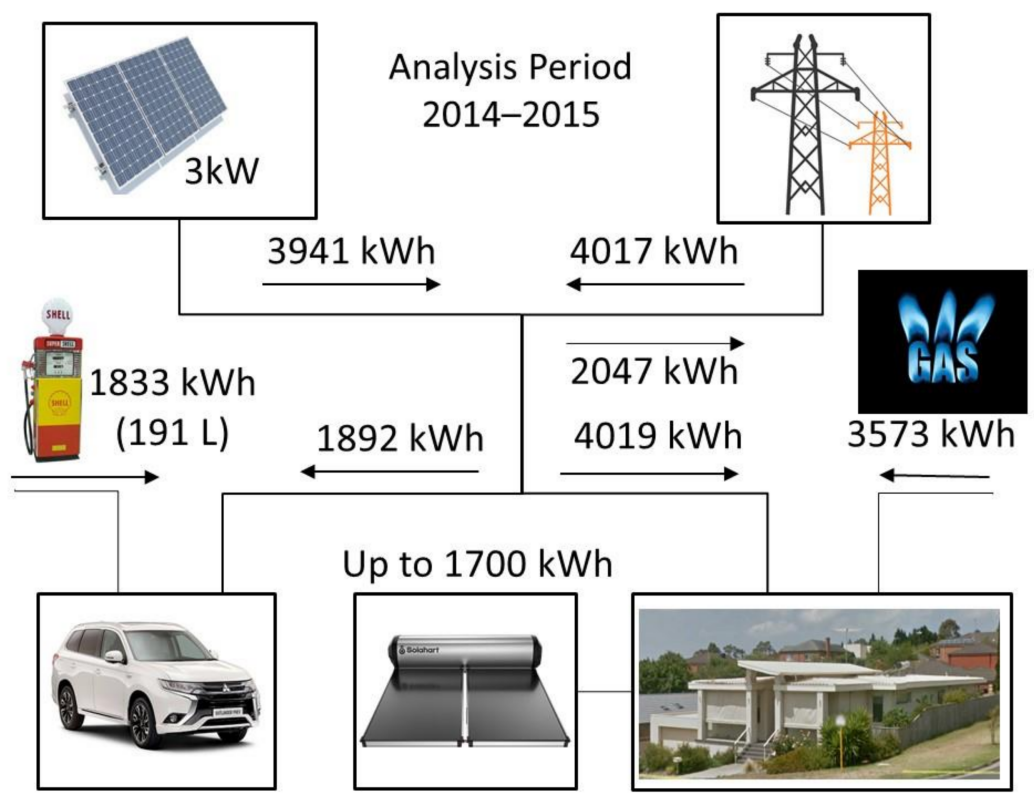

Figure 2. Household energy flows (July 2014-June 2015).

3.2.2. Varying the Solar PV System Size

How do the energy flows change when the solar PV system size changes? Scaling the solar energy by a factor $k$, new values for the imported and exported energy are:

$$
E_{G}^{\prime}(n)=E_{H}(n)-k E_{S}(n)
$$

Splitting the grid energy into imported and exported components

$$
E_{I}^{\prime}(n)=E_{H}(n)-k E_{S}(n)
$$

when $E_{H}>k E_{S}$; and:

$$
E_{E}^{\prime}(n)=k E_{S}(n)-E_{H}(n)
$$

otherwise. 
Summing Equations (4)-(6) over the year, the grid energy is:

$$
\sum_{n} E_{G}^{\prime}(n)=\sum_{n} E_{H}(n)-k \sum_{n} E_{S}(n)
$$

The imported energy when the load exceeds the solar harvest, $E_{H}>k E_{S}$ is:

$$
\sum_{n} E_{I}^{\prime}(n)=\sum_{n} E_{H}(n)-k \sum_{n} E_{S}(n)
$$

The exported energy when the harvest exceeds the load, is:

$$
\sum_{n} E^{\prime}{ }_{E}(n)=\mathrm{k} \sum_{n} E_{S}(n)-\sum_{n} E_{H}(n)
$$
tion (7):

Splitting the annual grid energy into imported and exported components in Equa-

$$
\sum_{n} E_{I}^{\prime}(n)-\sum_{n} E_{E}^{\prime}(n)=\sum_{n} E_{H}(n)-k \sum_{n} E_{s}(n)
$$

Therefore, the modified totals for the imported and exported energy can be determined for different system sizes by varying the value of the scale factor, $k$.

Figure 3 shows the result. The harvested solar energy changes linearly, from zero through 4.0 MWh at the nominal $3 \mathrm{~kW}$ system size. The imported grid energy falls from the zero solar estimated house load of $5.4 \mathrm{MWh}$, through $4 \mathrm{MWh}$ drawn with the installed $3 \mathrm{~kW}$ PV system to $2.94 \mathrm{MWh}$ with a $12 \mathrm{~kW}$ system. With a very large PV system, such that it cancels all imported energy during the day, the night-time energy of 2.1 MWh must still be imported [14]. The procedure for constructing Figure 3 is listed in Appendix A. Figure 3 also shows the net zero electrical energy point when the annual exported energy equals the imported energy.

Rearranging Equation (10):

$$
\sum_{n} E_{H}(n)-\sum_{n} E_{I}^{\prime}(n)=k \sum_{n} E_{S}(n)-\sum_{n} E_{E}^{\prime}(n)
$$

In other words, whatever the PV system size, the difference between the load energy and the imported energy is always equal to the difference between the harvested solar energy and the excess energy exported independent of the solar system size. 


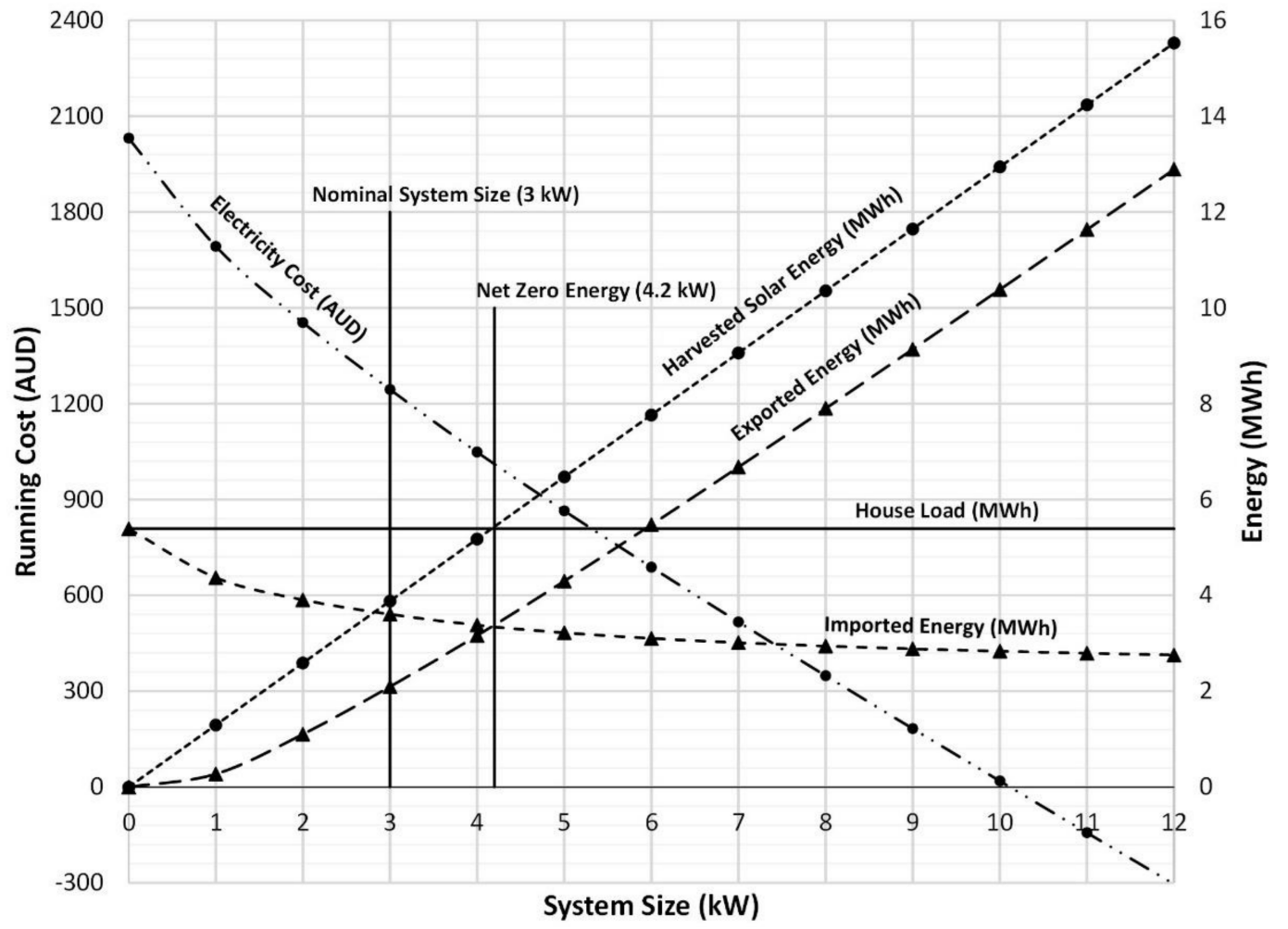

Figure 3. House 1: Energy flows and cost of electricity as a function of PV system size.

It is important to note that Figure 3 is constructed using the Smart Meter data, the solar PV data and the house load as described in Appendix A. By summing the imported energy when no solar energy is being generated at night, the lower limit on the imported energy can be calculated. Additionally, by recognising that when the solar system is small, all the solar energy feeds the load, completely displacing the imported energy; this means that the derivative (slope) of the imported energy at zero size is equal and opposite to the derivate of the harvested solar energy.

The cost of electricity, also shown in Figure 3, can then be calculated from the tariff (AUD 0.30/kWh flat rate; tariffs are for the year 2014-2015), the feed-in tariff (AUD 0.14/kWh) and the supply charge (AUD 1.14/day). For a small solar system, the harvested energy displaces imported energy at the import tariff. A large system harvests energy which, if greater than the house load, is exported at the feed-in tariff. A $1 \mathrm{~kW} \mathrm{PV}$ system creates an annual saving AUD 339 and at today's prices would cost about AUD 1000. Therefore, its payback period is just under 3 years. A $12 \mathrm{~kW}$ system saves AUD 2334.85 annually; if it costs AUD 12,000, it has a payback period of just over 5 years.

\subsection{3. $\mathrm{CO}_{2}$ Equivalent Emissions}

Table 3 summarises the $\mathrm{CO}_{2}$ equivalent emissions of the house and car for the $3 \mathrm{~kW}$ case. The estimated emissions increase when the plug-in hybrid is used without installing solar PV. This result applies in Victoria because the emissions factor for brown coal is so high [28]. (At time of writing, the reported emissions intensity of electricity in Victoria has fallen by $13 \%$ [29]). However, with solar PV, emissions are reduced by $65 \%$. On the other hand, the hybrid vehicle reduces petrol consumption by $84 \%$ and a pure electric vehicle would use no petrol at all. 
Table 3. Summary of $\mathrm{CO}_{2}$ equivalent emissions (July 2013-June 2015).

\begin{tabular}{|c|c|c|c|c|c|c|c|c|}
\hline \multirow[b]{2}{*}{ Grid (net) } & \multicolumn{2}{|c|}{ Before Solar } & \multicolumn{2}{|c|}{ Hybrid Only } & \multicolumn{2}{|c|}{ Solar PV Only } & \multicolumn{2}{|c|}{ Solar and Hybrid } \\
\hline & $3806 \mathrm{kWh}$ & $4301 \mathrm{~kg}$ & $5911 \mathrm{kWh}$ & $7090 \mathrm{~kg}$ & $78 \mathrm{kWh}$ & $88 \mathrm{~kg}$ & $1970 \mathrm{kWh}$ & $2226 \mathrm{~kg}$ \\
\hline Gas & $3842 \mathrm{kWh}$ & $711 \mathrm{~kg}$ & $3573 \mathrm{kWh}$ & $661 \mathrm{~kg}$ & $3573 \mathrm{kWh}$ & $661 \mathrm{~kg}$ & $3573 \mathrm{kWh}$ & $661 \mathrm{~kg}$ \\
\hline Petrol & $1113 \mathrm{~L}$ & $2451 \mathrm{~kg}$ & $191 \mathrm{~L}$ & $421 \mathrm{~kg}$ & 1207 L & $2658 \mathrm{~kg}$ & $191 \mathrm{~L}$ & $421 \mathrm{~kg}$ \\
\hline & Total & $7463 \mathrm{~kg}$ & Total & $8172 \mathrm{~kg}$ & Total & $3407 \mathrm{~kg}$ & Total & $3308 \mathrm{~kg}$ \\
\hline
\end{tabular}

\subsubsection{Working with Batteries}

At any time, the solar harvest exceeds the load of the house and it is in excess; or, the load exceeds the harvest and there is a shortfall. A battery stores energy for later use by charging from the excess solar energy or by importing energy from the grid. For this analysis, we exclude the case of charging from the grid, so the battery is charged when solar energy is in excess and provides energy when there is a shortfall, either at night or during the day, when the load exceeds the solar harvest. If the battery is fully charged, excess solar is exported to the grid; and, when discharged, the shortfall is imported (Figure 4).

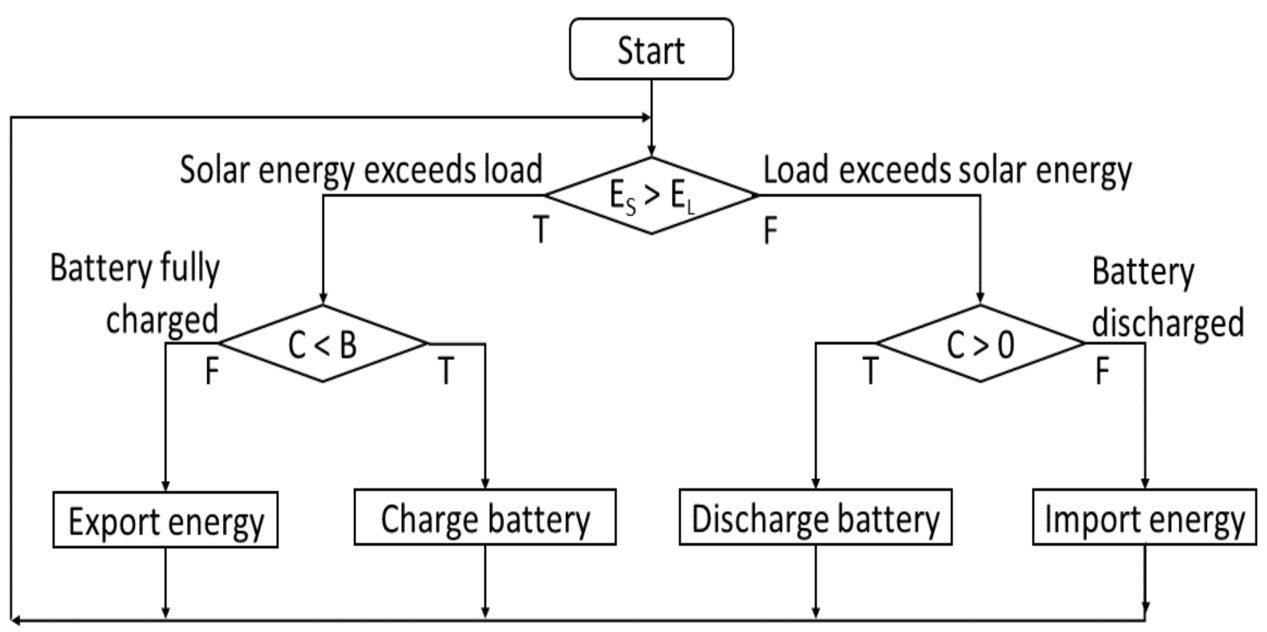

Figure 4. Simple battery control (solar charging only).

Battery storage can increase savings by reducing grid imports and exports of energy which arise from a mismatch of the solar harvest time and the energy usage time [11,12]. Figure 1 is an example of a period of gross mismatch for the house investigated, when an electric vehicle is charged from 16:15. By using battery storage systems the variable output of PV to the grid is minimised and anticipates better control $[3,5,11]$.

As shown in [14], a battery reduces the energy imported and exported depending on its size. In Figure 5, the effect of introducing a battery, as a function of its size, and for several PV system sizes is shown. These graphs are constructed as described in Appendix B. As the PV system size is increased, the imported energy drops and the exported energy increases. In each case, as the battery size grows, the energies fall from their initial values. Storing excess energy occurs during the day, when the solar energy exceeds the load. Savings are created by replacing the night-time energy drawn from the grid with energy drawn from the battery. Drawing energy from the battery will also occur during the day whenever the load is greater than the harvested solar energy. Savings from using a battery are limited. For example, a $12 \mathrm{~kW}$ PV system feeding a $14 \mathrm{kWh}$ battery (the capacity of a Tesla Powerwall II) saves about AUD 600 annually. 

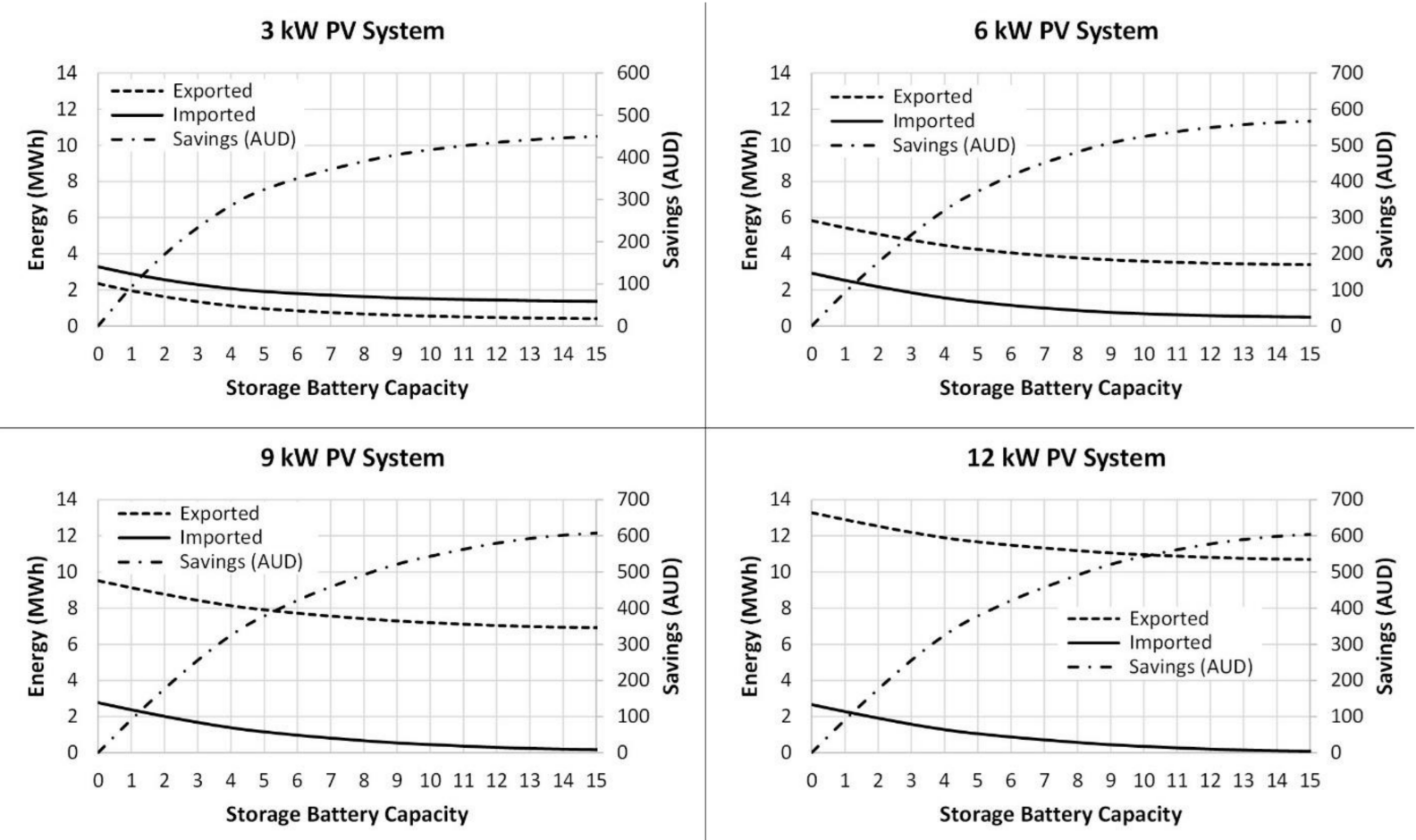

Figure 5. Energy flows and cost savings as a function of battery size and PV system size.

With a sufficiently large solar PV system, energy imported from the grid during the day will be minimised, in the limit, to zero. Without a battery, any excess solar energy will be exported. A battery will reduce the exported energy provided it is not fully charged. A large battery coupled with a large solar PV system can reduce the imported energy at all times to zero, allowing off-grid operation. Off-grid operation requires a battery large enough to support the house load over several days in mid-winter. However, then a sufficiently large enough solar PV system is required to charge the battery during short mid-winter days.

\subsection{House 2 with a $2.25 \mathrm{~kW}$ Solar PV System and a AUD 0.66/kWh Feed-In Tariff}

In the case of the second house, solar data was not available, only Smart Meter data. Without data on the solar harvest the effect of varying the solar system size cannot be calculated directly. However, we used the solar data from the first house as a proxy as the two houses are separated by $4.2 \mathrm{~km}$ and the solar intensity will be similar at both sites. This means that the effect of varying the solar system size and introducing battery storage can be calculated (Figure 6). Furthermore, this accounts for variable weather which will be similar at the two houses.

A problem with using proxy solar data is matching the two solar installations. Using nominal sizes, as here, suffers from differences in installation, such as orientation and tilt, and from differences in the actual power developed by each set of panels, independent of geometrical issues. Both systems are oriented towards north, but, at the first house, panels are tilted at about $5^{\circ}$, whereas, at the second, they are tilted at about $25^{\circ}$.We took the approach that the nominal power of each system equals its actual power, being alert for any major anomalies, such as times when the house load, calculated by subtracting the exported from the harvested energy, is negative. This is so for $3 \%$ of the readings. Increasing the proxy solar figure by $10 \%$ reduces this to $1.5 \%$.

The point in Figure 6 referring to the subsidised AUD 0.66 feed-in tariff is the annual running cost under an old, but still active, "Premium Feed-in Tariff". This subsidy was introduced in 2009 and closed in 2011. The annual saving for this case is AUD 1504 For a PV system of $2.5 \mathrm{~kW}$ costing about AUD 6000 in 2011 prices, this corresponds to payback 
period of 4 years. However, since electricity tariffs were lower at the time, the annual saving would have been greater and the payback period less. Figure 6 also shows the net zero energy point at which the annual exported energy is equal to the annual imported energy, and that a system size greater than $8.25 \mathrm{~kW}$ would reduce the running cost below that achieved with the AUD 0.66 feed-in tariff.

As solar energy is not available during the night, the total imported energy can never be zero without using battery storage. Indeed, the imported energy has a horizontal asymptote of 3.11 MWh independent of any scale error arising from the foreign solar data. This figure is obtained from the imported energy when the solar energy is zero. As it depends only on imported energy, the estimate is free of scaling errors and will be a good estimate.

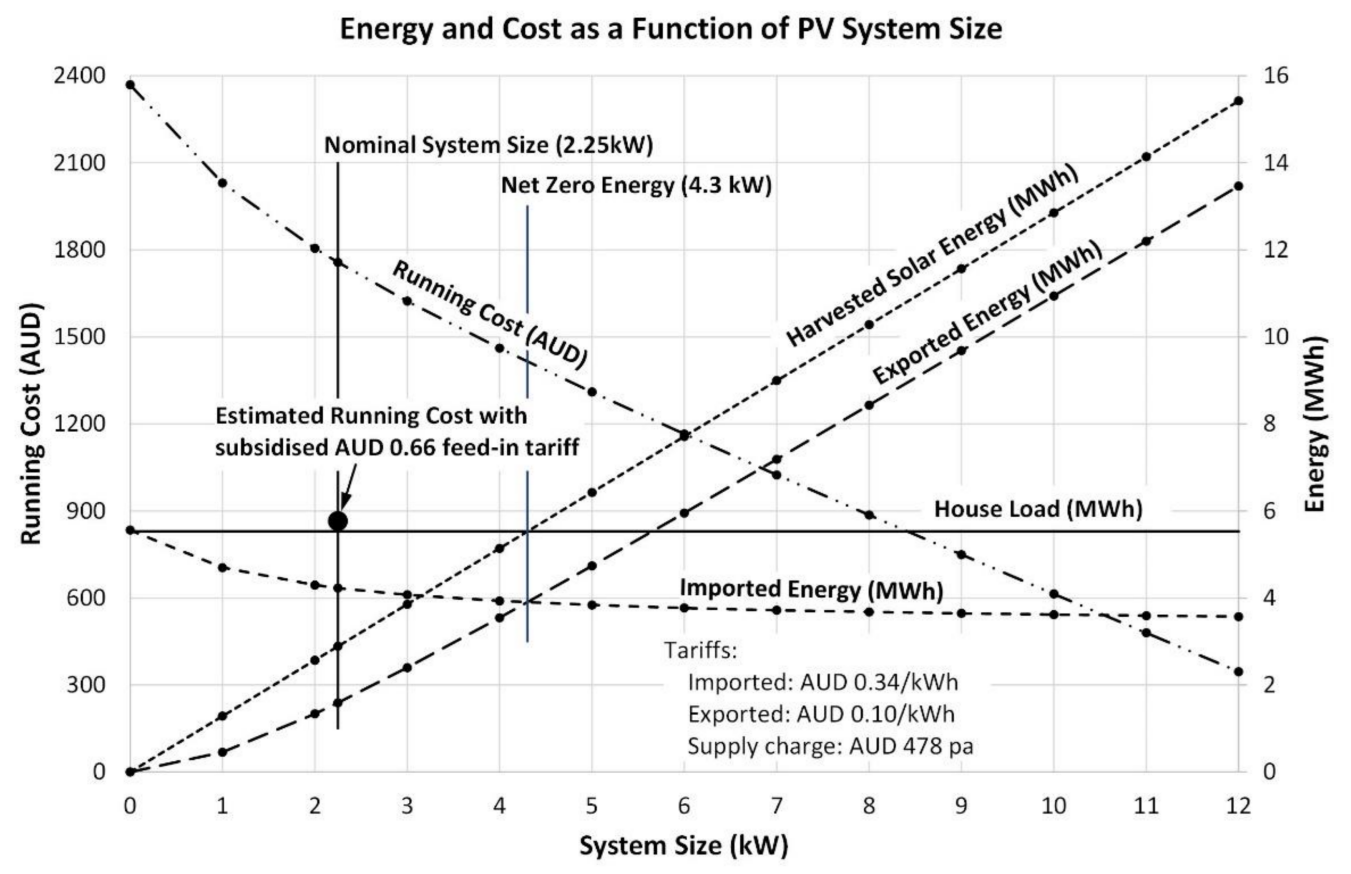

Figure 6. House 2: Energy flows and cost of electricity as a function of Solar PV system size.

To explore the question of how sensitive are readings taken from Figure 6 to errors in mismatching the target and reference solar PV system sizes consider Figure 7. This shows the modelled imported energy using both the nominal size of the proxy solar PV system and double that size. The imported energy is known and is independent of any mismatch of scale between the original and target systems. Such a mismatch will alter the estimate of the house load, which is the value of energy when the PV system size is assumed to be zero. Using the proxy solar energy unscaled, the house load is $5.53 \mathrm{MWh}$. If the proxy solar energy is doubled, the house load is estimated to be $8.42 \mathrm{MWh}$. Therefore, the actual house load is very sensitive to scaling errors. 


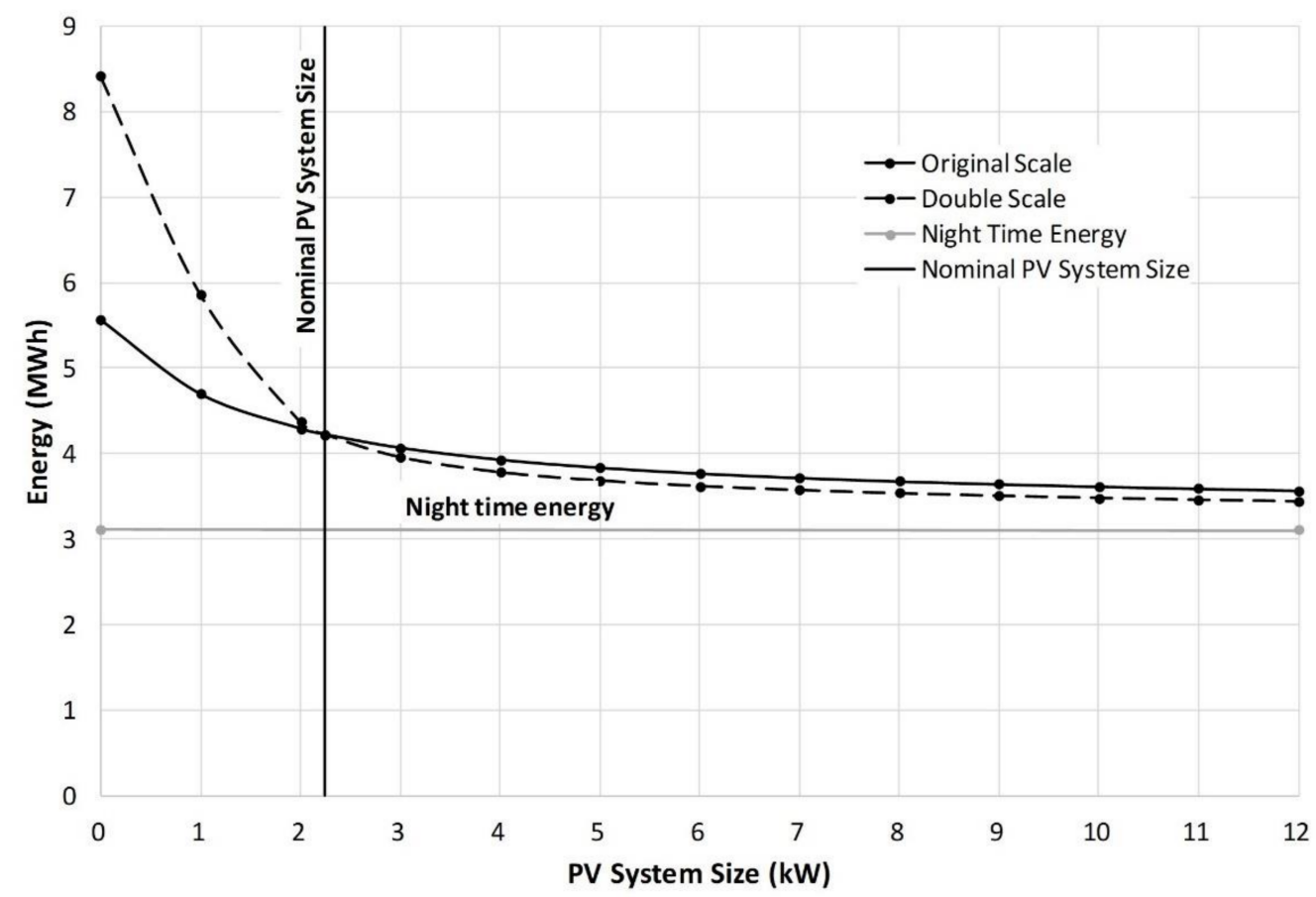

Figure 7. The effect of doubling the proxy solar data on the imported energy.

However, in the case of the target house, with a $2.25 \mathrm{~kW}$ PV system, the imported energy is $4.23 \mathrm{MWh}$, and the night-time energy is $3.11 \mathrm{MWh}$ as noted above. Therefore, the imported energy curve is confined between the imported energy at nominal size and the night-time energy. It is tightly controlled and a good estimate of imported energy. That is, for PV systems larger than the nominal, error arising from using the proxy solar data to estimate the imported energy is small.

On the other hand, the curve shows that estimates below the known, nominal size, are very sensitive to mismatches between the actual and proxy solar data. However, reducing the size of a solar PV system is probably not of interest in normal situations. The answers users would most likely seek is to the effect of increasing the size of a solar PV system.

\subsection{1. $\mathrm{CO}_{2}$ Equivalent Emissions}

Table 4 lists the net grid energy for House 2, which shows that the $\mathrm{CO}_{2}-\mathrm{e}$ is large. This is because the installed solar system is much smaller than that required to achieve net-zero energy. Figure 6 shows that a system of about $4.2 \mathrm{~kW}$ is required to achieve this. However, because the subsidy would no longer be applied, the annual running cost would rise by about AUD 500 .

Table 4. House 2: $\mathrm{CO}_{2}$ equivalent emissions (2018).

\begin{tabular}{ccc}
\hline & Energy & $\mathbf{C O}_{2}$-e \\
\hline Grid (net) & $2637 \mathrm{kWh}$ & $2822 \mathrm{~kg}$ \\
Gas (est) & $4863 \mathrm{kWh}$ & $900 \mathrm{~kg}$ \\
Diesel (est.) 25,000 km & $2750 \mathrm{~L}$ & $7483 \mathrm{~kg}$ \\
\hline & Total & $11,205 \mathrm{~kg}$ \\
\hline
\end{tabular}

\subsubsection{Introducing Batteries}

As Figure 7 shows, for House 2, the energy drawn at night in 2018 is $3.11 \mathrm{MWh}$. Figure 8 shows the total annual imported and exported energy and cost savings as a function of battery size for various sizes of the solar PV system. The maximum possible saving 
is about AUD 700 with a $15 \mathrm{~kW}$ battery and a $12 \mathrm{~kW}$ PV system. A Tesla Powerwall II would save about AUD 600.

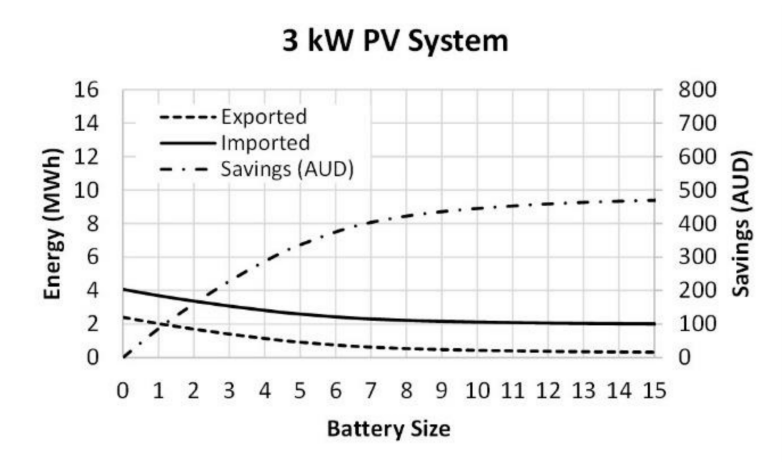

9 kW PV System

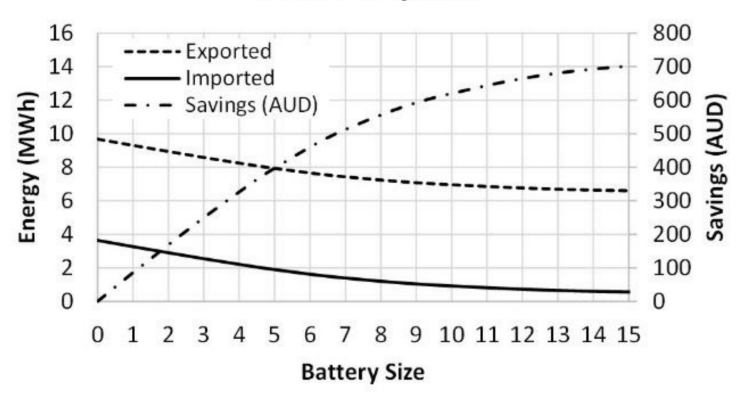

\section{6 kW PV System}

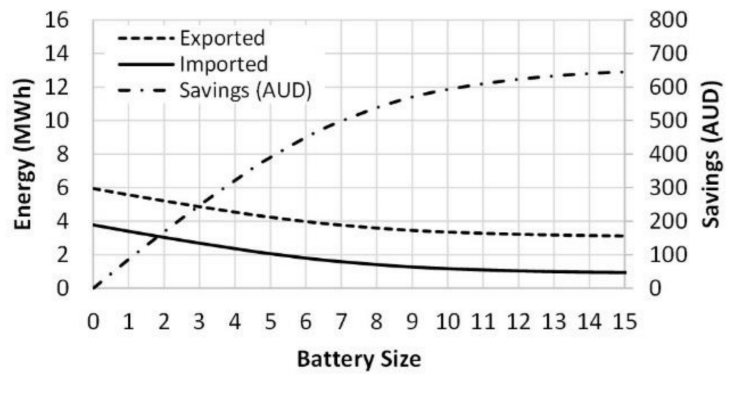

12 kW PV System

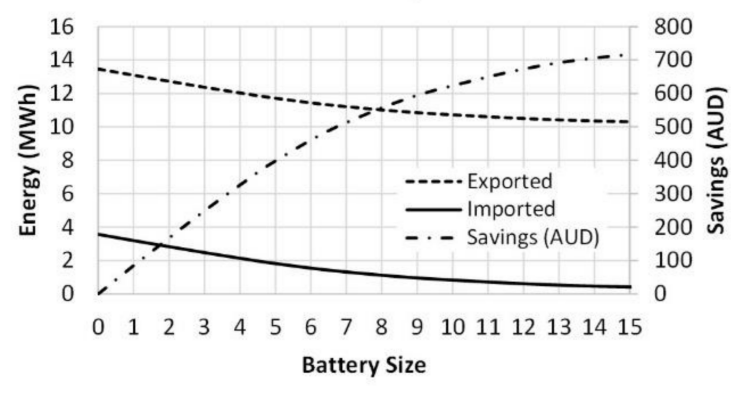

Figure 8. House 2: Energy flows and cost savings as a function of battery size.

The maximum possible savings resulting from installing a battery is higher in the second house than the first, which can be traced to a higher load overall, but mainly at night.

\subsection{House 3 with No Solar PV System}

Information for this house is available only from the Smart Meter data. This means that the load to be served is known, but the night-time energy cannot be deduced from the Smart Meter data because there is no solar energy data. There are two ways to estimate the night-time component, by using the proxy solar data or by using times for sunrise and sunset at the house location.

Figure 9 shows the energy flows and cost of electricity for House 3 which has no solar PV system. Nevertheless, it is similar to Figures 3 and 6. The parameters which set the curves for this house are the house load (4.6 MWh), the night-time load (2.1 MWh), the ratio of annual energy harvest to PV system size (1.3 MWh $/ \mathrm{kW}$ ), the grid tariff (AUD 0.341/kWh) and the feed-in tariff (AUD 0.106/kWh).

In a house with no solar PV, the nominal size is zero and the curve of imported energy is confined between the total house load and the night-time house load. A solar PV system size of $3.5 \mathrm{~kW}$ will achieve annual net-zero emissions, and a $12 \mathrm{~kW}$ system will reduce running cost to zero.

Estimating night-time load is a problem without solar data. Here, the solar data from House 1 is used as a proxy and can be used as a mask to select the load when solar energy is unavailable. Otherwise, times of sunrise and sunset at the house can be used. 


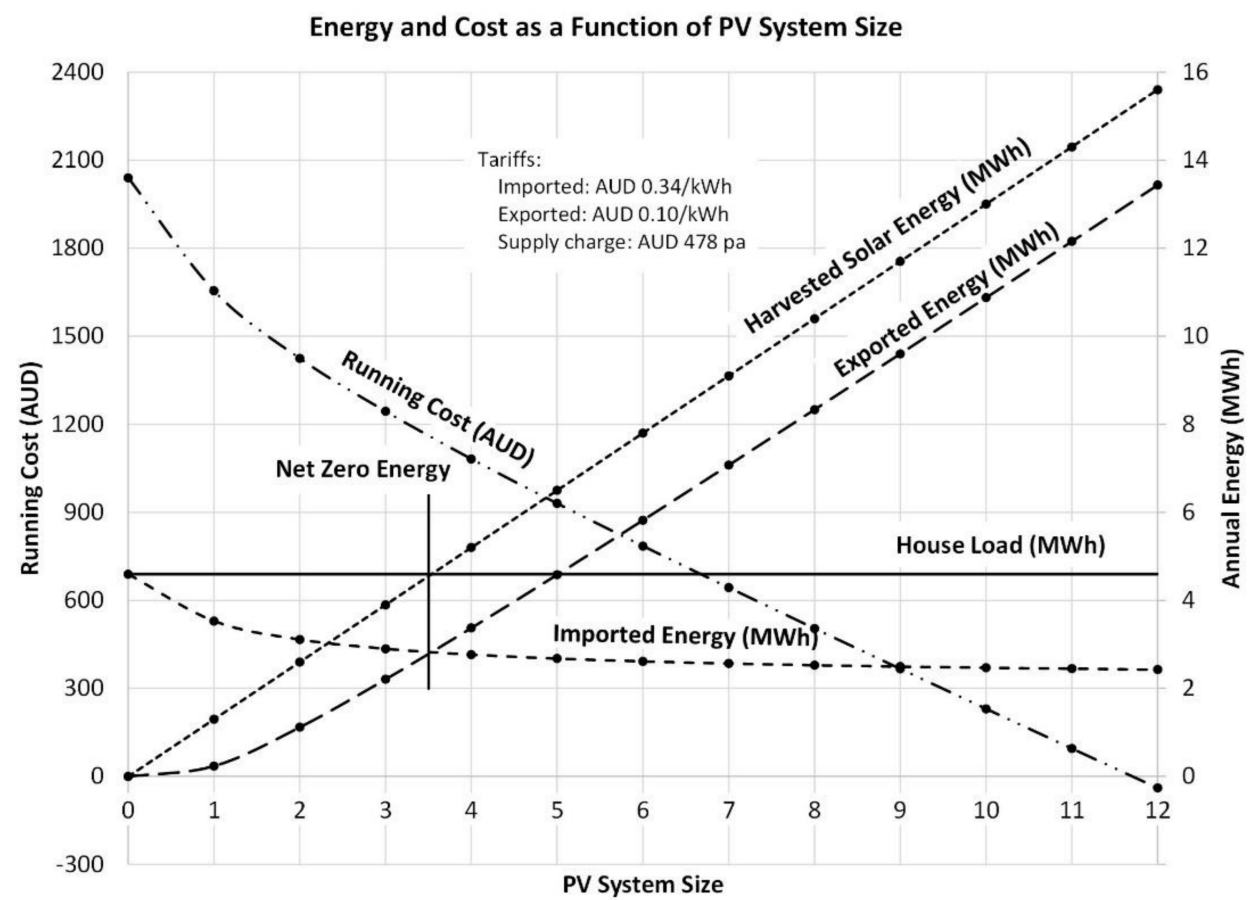

Figure 9. House 3: Energy flows and cost of electricity.

\subsubsection{Introducing Batteries}

Batteries in House 3 have characteristics similar to House 1 because the night-time energy is similar (Figure 10).

3 kW PV System

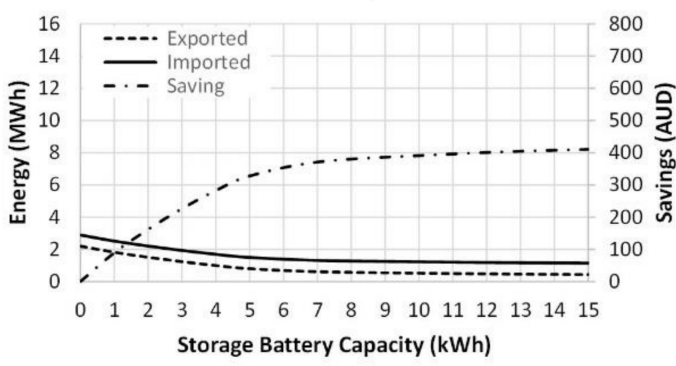

3 kW PV System

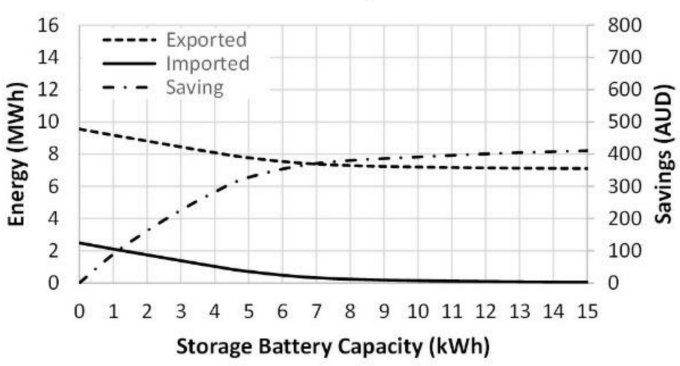

3 kW PV System

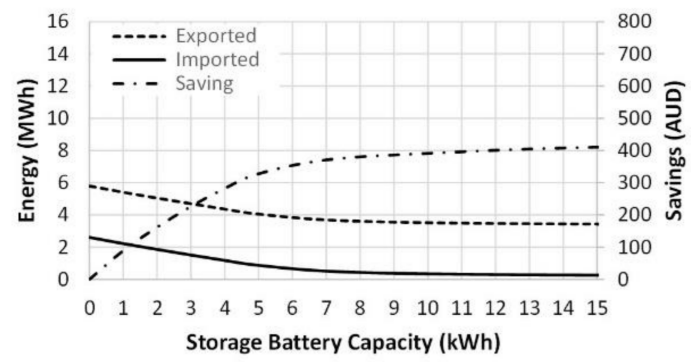

3 kW PV System

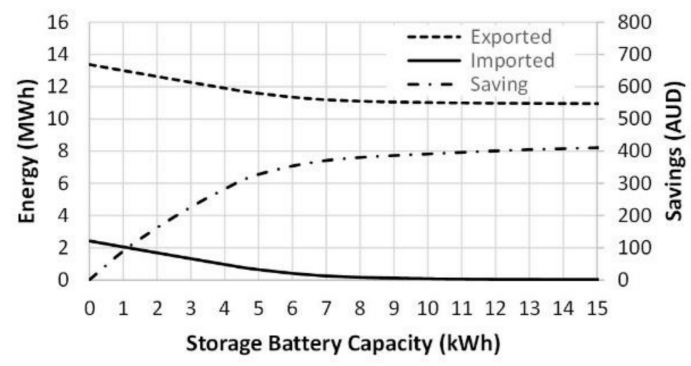

Figure 10. House 3: Energy flows and cost savings as a function of battery size. 


\subsection{2. $\mathrm{CO}_{2}$ Equivalent Emissions}

Table 5 lists the net grid energy and $\mathrm{CO}_{2}$-e for House 3. A solar PV system of about $3.5 \mathrm{~kW}$ would achieve net-zero grid energy, and so zero $\mathrm{CO}_{2}$-e annually. Unfortunately, gas and petrol data became unavailable since the project began.

Table 5. House 3: $\mathrm{CO}_{2}$ equivalent emissions (2018).

\begin{tabular}{ccc}
\hline & Energy & CO $_{2}$-e \\
\hline Grid (net) & $4574 \mathrm{kWh}$ & $4711 \mathrm{~kg}$ \\
Gas & $\mathrm{n} / \mathrm{a}$ & \\
Petrol & $\mathrm{n} / \mathrm{a}$ & \\
\hline & Total & $4711 \mathrm{~kg}$ \\
\hline
\end{tabular}

\section{Comparing the Three Houses}

The data for the three houses is collated in Table 6 . Houses 1 and 3 are similar, as they have a similar night-time load, but House 1 also supports charging the hybrid car. House 1 is 14 years old, built with an eye to energy performance with double glazing, and insulation of walls, ceiling and floor, supports the hybrid car at no extra cost. Not listed in the table are the avoided cost of petrol for the hybrid. The night-time load in House 2 is $50 \%$ greater. One difference may be that they are a working couple, whereas the occupants of Houses 1 and 3 are retired.

Table 6. Comparison of the three houses (2018 data).

\begin{tabular}{|c|c|c|c|}
\hline & House 1 & House 2 & House 3 \\
\hline Grid tariff & & AUD $0.341 / \mathrm{kWh}$ & \\
\hline Feed in tariff & & AUD $0.106 / \mathrm{kWh}$ & \\
\hline Supply charge & & AUD 526.05 & \\
\hline Annual load & $5.4 \mathrm{MWh}$ & $5.5 \mathrm{MWh}$ (est.) & 4.6 MWh \\
\hline Night-time load & $2.1 \mathrm{MWh}$ & 3.1 MWh & $2.1 \mathrm{MWh}$ \\
\hline Installed PV system & $3 \mathrm{~kW}$ & $2.25 \mathrm{~kW}$ & $\mathrm{n} / \mathrm{a}$ \\
\hline PV system size achieving net zero electrical energy & $4.2 \mathrm{~kW}$ & $4.2 \mathrm{~kW}$ & $3.5 \mathrm{~kW}$ \\
\hline Electricity cost without solar & AUD 2164 (est.) & AUD 2040 (est.) & AUD 2085 \\
\hline Electricity cost with installed PV system & AUD 1399 & $\begin{array}{l}\text { AUD } 850 \text { (AUD 0.66/kWh FiT) } \\
\text { AUD } 1750 \text { (AUD 0.10/kWh FiT) }\end{array}$ & $\mathrm{n} / \mathrm{a}$ \\
\hline Annual saving & AUD 765 & $\begin{array}{l}\text { AUD } 1190 \text { (AUD 0.66/kWh FiT) } \\
\text { AUD } 290 \text { (AUD 0.10/kWh FiT) }\end{array}$ & \\
\hline Electricity cost with $6 \mathrm{~kW} \mathrm{PV} \mathrm{system}$ & AUD 904 & AUD 1150 (AUD 0.10/kWh FiT) & AUD 785 \\
\hline Annual saving & AUD 1260 & AUD 890 & AUD 1300 \\
\hline Maximum possible saving with battery & AUD 642 & AUD 827 & AUD 560 \\
\hline Saving with $6 \mathrm{kWh}$ battery & AUD 413 & AUD 445 & AUD 437 \\
\hline $\begin{array}{l}\text { Total saving with } 6 \mathrm{~kW} \text { PV system and } 6 \mathrm{kWh} \\
\text { battery }\end{array}$ & AUD 1673 & AUD 1335 & AUD 1737 \\
\hline
\end{tabular}

\section{Matching the Solar PV Harvest to the House Load}

The two factors to consider, first, in sizing a solar PV system and battery are the load and the solar harvest. Is the daily solar harvest sufficient to support the load for the whole day, in particular at night when there is no solar energy available? Figure 11 shows the daily harvest from a $10 \mathrm{~kW}$ PV system and the load for House 1. Because of the latitude of the house, the harvest from a PV system peaks in the summer months and falls in the winter months. The shorter days and the panels flat on a $5^{\circ}$ sloping roof emphasise the variation. From about the beginning of September to the beginning of April, the solar harvest is usually sufficient to support the load, the excess being exported to the grid. In the remaining months, the solar harvest would be insufficient on a number of days. When the harvested energy is insufficient, energy is imported from the grid. 
The $10 \mathrm{~kW}$ PV system covers 109 days of the 153 from 1 April to 31 August. A larger PV system will make up for some of the remaining days. For example, if the minimum harvest on a particular day is $10 \mathrm{kWh}$, but the load is $20 \mathrm{kWh}$, the system size would need to be doubled to compensate. A $20 \mathrm{~kW}$ PV system will cover an extra 33 days for a total of 144 of the 153 days. The extra capacity of $10 \mathrm{~kW}$ covers one third of the days covered by the first $10 \mathrm{~kW}$ and so is less economic.

Figure 11 does not show that the energy harvested must be stored in a battery for later use at night. In Figure 12, the house load has been filtered to exclude the load energy when solar energy is being harvested; what remains is the night load, averaging $8.4 \mathrm{kWh}$ a day. The imported energy, without a battery, exceeds the night load somewhat, because some energy is imported during the day when the load exceeds the solar harvest. Employing a battery (10 kWh in Figure 12), harvested energy can be stored, so that the imported energy is significantly reduced, but not completely, saving $2.31 \mathrm{MWh}$ in the year. Of course, a $10 \mathrm{kWh}$ battery may reduce the night time load by, at most, $10 \mathrm{kWh}$.

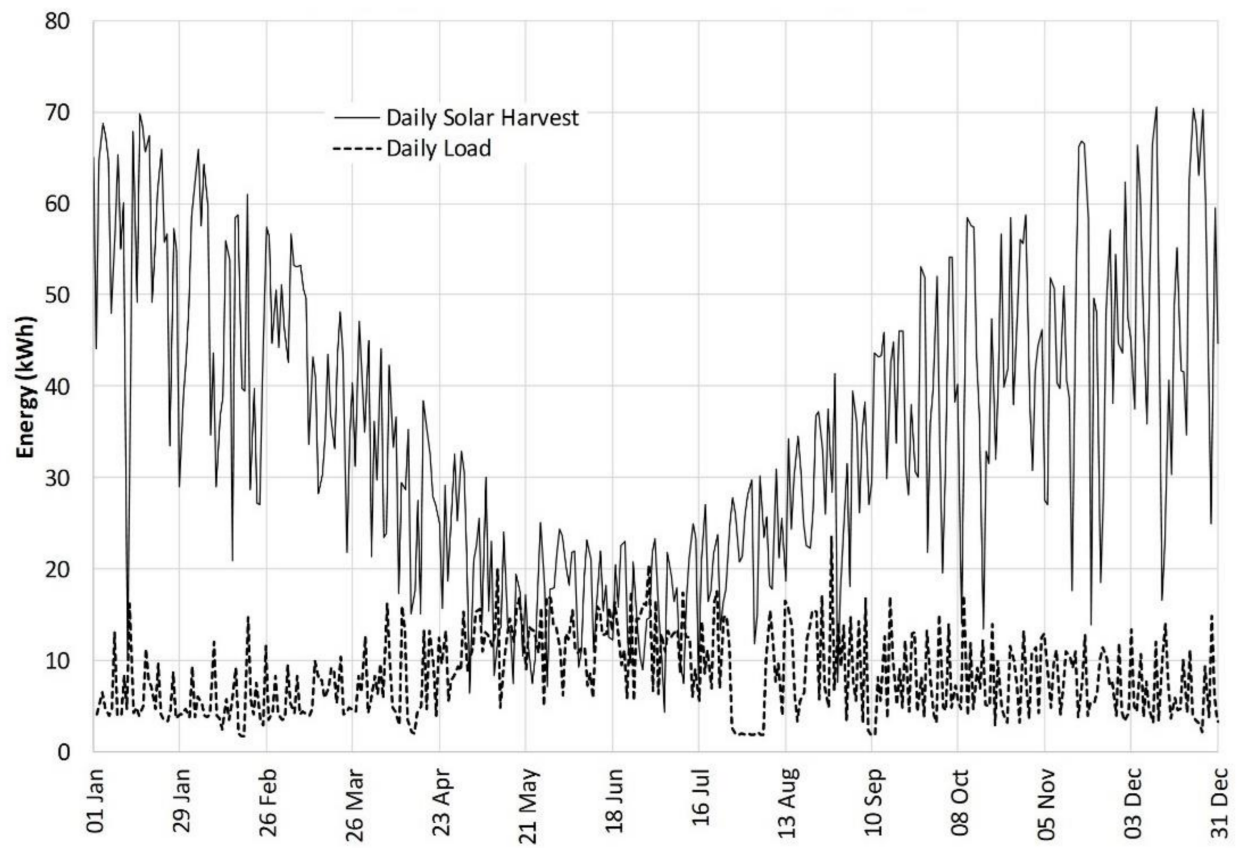

Figure 11. Daily $10 \mathrm{~kW}$ PV solar harvest and load for House 1.

Of interest is the higher night-time load, averaging $10.5 \mathrm{kWh}$ a day, in the colder months between 1 April and 31 August. In the warmer months, the average night-time load is $6.9 \mathrm{kWh}$ a day. This difference is because winter night times are longer, there is less opportunity to charge the vehicle in daytime hours and energy for lighting and driving fans associated with gas heating is higher. 


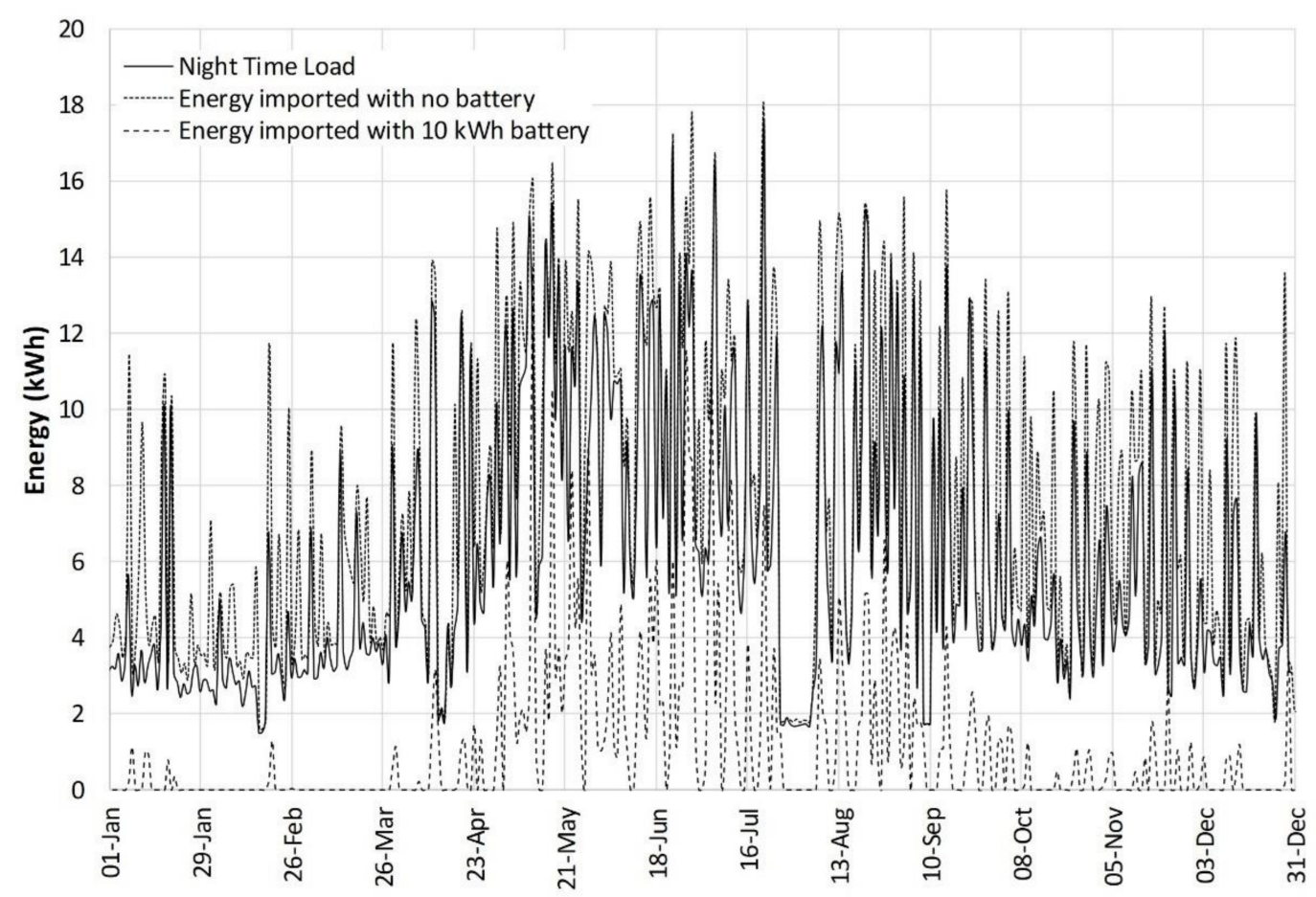

Figure 12. Night load and energy imported with and without a $10 \mathrm{kWh}$ battery.

\section{Guidance}

Figures 3, 6 and 9 show the performance of each house as a function of PV system size. These figures depend on the house load, the night-time load, the solar PV system size, the imported and exported grid energy, and the tariffs in place. The solar PV data for House 1 was collected, but, in the absence of solar data, the harvest may be determined from data supplied by [25]. The Annual Averaged Direct Normal Radiation reported for the location of House 1 is $4.16 \mathrm{kWh} / \mathrm{m}^{2} /$ day. The $3 \mathrm{~kW}$ system occupies $20 \mathrm{~m}^{2}$ and is about $13 \%$ efficient, so harvests $3.95 \mathrm{MWh}$ per annum. This sets the gradient of the Solar Harvest line. The actual measured harvest shown in Figure 2 is $3.94 \mathrm{MWh}$.

Smart Meter data provides the values of imported and exported energy for the nominal PV system size in half hourly time intervals. The house load can be evaluated from Equation (3). By excluding Smart Meter data when solar energy is being exported, what remains is the night-time energy imported from the grid. This provides the lower limit of the imported energy. The energy costs follow as described earlier. Then the solar energy can be scaled and the imported and exported energy recalculated using Equations (8) and (9). Totalised over the whole year gives the data for Figures 3, 6 and 9 determined similarly, except that the solar data is supplied from that determined for the first house. These graphs depend directly on the data gathered, and no simulation or modelling is done, except for modelling the solar energy at House 2 and House 3 by proxy from House 1 . This is a key result of this work.

The imported energy decreases from the house load to the night-time load as the PV system size is increased, and it is tightly constrained by these two load quantities as Figure 7 shows. That is, errors in PV system size when using the solar data from the first house will not be serious. For the same reason, without solar data to model half hourly variations, the annual imported energy as a function of PV system size may be modelled by fitting a curve to the house load, the night-time load and the initial gradient of the imported energy curve.

Figures 5, 8 and 10 show the cost saving achievable with a battery. This saving is limited by the night-time load, which a battery can supply after being charged by the PV system. Figure 12 shows the state of charge of the battery throughout the year. The winter 
performance is critical. If the battery is chosen to cater for the night-time load in winter, how big does the PV system need to be to charge it sufficiently?

The process of estimation starts from the house load. Knowing that, solar PV systems may be chosen to achieve objectives such as:

- $\quad$ annual net zero electrical energy use ( 4.2 kW for House 1);

- $\quad$ net zero electrical energy use from 1 April to 31 August ( 7 kW for House 1);

- annual net zero running cost without a battery ( 10 kW for House 1);

- matching average winter night-time load (10.5 kWh for House 1).

The battery capacity may be chosen to lie between a lower limit such that the battery is frequently charged in winter by the solar PV system and an upper limit such that it is rarely discharged by the load overnight, but also not always fully charged at night. This latter constraint implies that the solar PV system is large enough to frequently charge the battery in winter. The average night-time load from 1 April to 31 August 2018 is $8.15 \mathrm{kWh}$ with a standard deviation of $3.91 \mathrm{kWh}$. Assuming a normal distribution, a $10 \mathrm{kWh}$ battery would cover $68 \%$ of the night time loads. Based on our data, a $10 \mathrm{kWh}$ system will support the total load on 109 of 153 days in these months, or $71 \%$.

\section{Realisations}

During the course of this work, we realised a number of factors which affect the performance of solar PV systems. First, latitude is an important element. The disparity between summer and winter performance is greatly affected by latitude. At the latitude of this study, $38^{\circ} \mathrm{S}$, winter and summer harvests differ significantly, by as much as a factor of 3 or 4 (Figure 11). This is because a mid-winter day is two-thirds the length of a midsummer day and the maximum altitude of the sun changes from $76^{\circ}$ at midsummer to $29^{\circ}$ at midwinter. On the other hand, in tropical latitudes, the altitude remains high all year round and the day length changes little, so there is less need to design for winter performance. For a given load, a smaller PV system is likely to suffice, and winter performance will not be so critical.

Secondly, the night-time load is significantly higher in winter, $60 \%$ in the case of House 1. This is not evident from the daily load data, but only when the night-time load itself is studied. Furthermore, the winter night-time load is the important case in considering battery size.

Thirdly, the availability of Smart Meter data is important. If a solar PV system is not installed, the Smart Meter data is the house load. It may be combined with sunrise and sunset times to extract the night-time load. Hence, combined with the efficiency of the solar panels, the performance of a new solar PV system can be calculated accurately.

Finally, if records of the solar harvest are unavailable, either because no system is installed, or because records are not available, records from a nearby property can be used as a proxy, because weather conditions are similar. It turns out that the imported energy is controlled strongly by the house load and the night-time load and so can be predicted accurately (Figure 7).

Finally, newly built houses are at a disadvantage in estimation as there is no record of load to be used in the calculation of performance as, for example, in Figure 5. Theoretical estimates of load would need to be used.

\section{Advantages and Disadvantages}

The advantages of the work presented are:

- The methods are based on actual data collected from Smart Meters which the power supply company uses to bill data. Our two methods are empirical, and work from first principles.

- Actual solar PV data is used if available. If not, solar data from a nearby Solar PV system may be used as a proxy. This caters for similar weather conditions at the two houses. 
- The methods for calculating system performance from this data are simple. They are outlined in Apendix A and Appendix B. The methods can be implemented on a simple spreadsheet.

- The parameters required for the two methods are readily obtainable from the Smart Meter and Solar data, namely, imported energy, energy imported at night (no solar energy), exported energy, solar energy harvested and tariffs.

- No modelling is used except for scaling the sizes of the PV system and battery system. The disadvantages of the work presented are:

- Management of heavy loads have not been considered. The power required from batteries has not been taken into account.

- Losses in the system have not been allowed for.

- Managing batteries in winter by charging from the grid when necessary has not been considered.

- Using the electric vehicle to feed energy into the house has not been considered.

- Optimisation methods have not been applied to size batteries.

\section{Summary and Conclusions}

This study began with House 1 when a $3 \mathrm{~kW}$ PV system was installed and a hybrid vehicle was purchased [13]. Since then, data has been collected from the Smart Meter, solar data from the PV system and charging data from the vehicle. It was found that the hybrid vehicle avoided the use of about $1000 \mathrm{~L}$ of petrol annually and the solar PV system compensated for charging the vehicle, so electricity costs did not change significantly. The financial saving was from avoiding the purchase of petrol.

Smart Meter data was used to study the energy use in Houses 2 and 3. However, as the solar energy data was not available at these houses, the data from House 1, $4.2 \mathrm{~km}$ distant, and so subject to much the same weather conditions, was used as a proxy. This enabled the house load, in the absence of solar data to be estimated. Then the performance of the house, as the size of the solar PV system was increased, could be estimated. There is uncertainty in estimating the house load and consequently, the energy and cost benefits from increasing the PV system size. However, the imported energy is tightly bounded above by net house load (imported less exported energy) and below by the unavoidable night-time load.

When batteries are considered, the night-time energy is readily obtainable from Smart Meter and solar data, by summing the imported energy when the solar energy is zero. Batteries, by load shifting, can be used to reduce this night-time load. However, using an electric vehicle offers a greater monetary benefit than household batteries because of the high cost of petrol. (While writing this paper, a rebate supporting batteries of up to AUD 6000 became available which has not been accounted for).

The size of the PV system and the battery depends on the house load. The annual average load in the original house is about $13 \mathrm{kWh} /$ day. The average night-time load is $8.4 \mathrm{kWh}$ annually, but critically, this rises to $10.5 \mathrm{kWh}$ in the months from April to August. The load is expected to be far less sensitive to seasonal variation, so will be better for estimation. A $10 \mathrm{kWh}$ battery, matching the average winter night-time load, will cater for most behaviours.

The $3 \mathrm{~kW}$ PV reference system harvests an annual average of $10.5 \mathrm{kWh} /$ day. This is low because the panels are flat on a steel colorbond roof. Larger PV systems harvest more energy and significantly reduce energy costs. However, the night-time energy can be reduced only by using batteries. At present, batteries are not very cost effective, but PV systems are.

The power rating of batteries was not considered in this paper. However, it is important to consider the peak power required by the load. For example, as Figure 1 shows, $1.5 \mathrm{kWh}$ is being drawn in $30 \mathrm{~min}$, which is a power rating of $3 \mathrm{~kW}$.

Upon reflection, several important lessons have been learned in this study and in writing this paper. These may appear obvious but need to be brought to the forefront if considering solar PV size in conjunction with batteries: 
- Winter periods yield about $1 / 3$ or less energy harvest than peak summer.

- If there is no harvested energy to store in batteries in winter for evening use, batteries are superfluous, since there could be about one-third to half of the year where no solar $\mathrm{PV}$ storage is provided for in the night-time hours.

- A hybrid or electric vehicle makes more economic sense than a large battery for a household, since petrol costs are avoided.

- A larger solar PV system with a smaller storage battery may prove to be more viable since there will be both excess export to the grid in summer and some storage for evening use in winter. In fact, sizing the battery for winter evening use is probably the most sensible approach given the relatively low cost and rebates at present on solar PV systems.

- Given that Smart Meter data yields the average daily energy use in winter at night, this is useful for selecting battery size.

- Private $\mathrm{CO}_{2}$ emission reductions in the State of Victoria are achieved mainly by installing a Solar Photovoltaic System. Reducing grid supplied energy displaces the use of brown coal.

- Lastly, we used recorded data in this analysis to understand the problem from first principles. Using optimisation techniques may provide answers, but often without explanation. Our approach shows how possible answers are bounded physically.

Author Contributions: All authors contributed equally to this paper. All authors have read and agreed to the published version of the manuscript.

Funding: This research received no external funding.

Institutional Review Board Statement: Not applicable.

Informed Consent Statement: Not applicable.

Data Availability Statement: Data available on request due to restrictions e.g., privacy or ethical. The data presented in this study are available on request from the corresponding author. The Smart Meter data are not publicly available as it has been obtained from a private power distribution company using identification information obtained from private householders. The authors have no commercial association with the power distribution company. The solar PV data has been obtained from the private company which monitors the PV system.

Acknowledgments: The authors wish to acknowledge those householders who kindly provided their grid and solar data.

Conflicts of Interest: The authors declare no conflict of interest.

\section{Appendix A. Constructing the Graphs in Figures 3, 6 and 9}

The following procedure was used:

- The format of Smart Meter files is defined in [30]. They are CSV files readable by programs such as Microsoft Excel. Each line corresponds to a day with 48 readings of energy taken every half hour. There are two blocks, one of imported energy and one of exported energy. A program is used to reformat the data into lines which contain both imported and exported energy for a particular half hour. One year of data is used.

- The harvested solar energy data is downloaded from the provider and consists of readings taken every $15 \mathrm{~min}$. Every consecutive pair needs to be converted into a half hourly reading.

- Both sets of data are then merged into a single file of imported, exported and solar energy for each half hour.

- The house load for each time interval is then calculated using Equation (3).

- Summing each type of data, the annual imported, exported, harvested and load energies are found.

- The harvested energy can be scaled to a number of solar PV system sizes and the resulting modified values of imported and exported energy can be calculated for each 
interval using Equations (5) and (6). The new annual values of imported and exported energy are found by summing these values for each system size.

- The cost of energy can then be calculated using the tariff structure.

- The resulting data is then plotted as a function of PV system size.

\section{Appendix B. Constructing the Graphs in Figures 5, 8 and 10}

The following procedure was used (see Figure 4):

- The data for a given size of solar PV system (date and time, imported energy, exported energy, harvested energy, and load energy is used).

- The battery size is selected.

- If the harvested energy exceeds the load, during an interval, and the battery is not fully charged, the excess energy is added to the battery instead of being exported.

- If the battery is fully charged, the excess energy is exported.

- If the load exceeds the harvested energy, the shortfall is drawn from the battery.

- If the battery discharged, energy is imported from the grid.

- The exported and imported energy is totalized for the whole year

- The calculation is repeated for a range of battery sizes and the calculated annual exported and imported energy is plotted against battery size.

- The cost of energy can be calculated for each battery size and compared with the cost when the battery is absent. The difference is the saving created by the battery.

\section{References}

1. Baulch, B.; Do, T.D.; Le, T.-H. Constraints to the uptake of solar home systems in Ho Chi Minh City and some proposals for improvement. Renew. Energy 2018, 118, 245-256. [CrossRef]

2. Halder, P. Potential and economic feasibility of solar home systems implementation in Bangladesh. Renew. Sustain. Energy Rev. 2016, 65, 568-576. [CrossRef]

3. Hong, X.L.; Horan, P.; Luther, M.B.; Ahmed, T.M. Informed decision making of battery storage for solar-PV homes using smart meter data. Energy Build. 2019, 198, 491-502. [CrossRef]

4. Chapman, A.J.; McLellan, B.; Tezuka, T. Residential solar PV policy: An analysis of impacts, successes and failures in the Australian case. Renew. Energy 2016, 86, 1265-1279. [CrossRef]

5. Horan, P.; Luther, M.B. Going Solar: The ramifications. In Fifty years later: Revisiting the role of architectural science in design and practice. In Proceedings of the 50th International Conference of the Architectural Science Association, Adelaide, Australia, 7-9 December 2016; pp. 1-10.

6. Nicholls, A.; Sharma, R.; Saha, T. Financial and environmental analysis of rooftop photovoltaic installations with battery storage in Australia. Appl. Energy 2015, 159, 252-264. [CrossRef]

7. Turner, L. Energy Storage Update, Renew, 145, October 2018. pp. 18-23. Available online: https://renew.org.au/renewmagazine/solar-batteries/energy-storage-update/ (accessed on 2 May 2021).

8. Vorrath, S. Australians Installed 22,661 Home Battery Systems in 2019. 2020. Available online: https:/ / onestepoffthegrid.com.au/ australians-installed-22661-home-battery-systems-in-2019/ (accessed on 19 April 2020).

9. Rowe, M.; Yunusov, T.; Haben, S.; Holderbaum, W.; Potter, B. The Real-Time Optimisation of DNO Owned Storage Devices on the LV Network for Peak Reduction. Energies 2014, 7, 3537-3560. [CrossRef]

10. Ren, Z.; Grozev, G.; Higgins, A. Modelling impact of PV battery systems on energy consumption and bill savings of Australian houses under alternative tariff structures. Renew. Energy 2016, 89, 317-330. [CrossRef]

11. Hassan, A.S.; Cipcigan, L.; Jenkins, N. Optimal battery storage operation for PV systems with tariff incentives. Appl. Energy 2017, 203, 422-441. [CrossRef]

12. Hoppmann, J.; Volland, J.; Schmidt, T.S.; Hoffmann, V.H. The economic viability of battery storage for residential solar photovoltaic systems-A review and a simulation model. Renew. Sustain. Energy Rev. 2014, 39, 1101-1118. [CrossRef]

13. Muenzel, V.; Mareels, I.; De Hoog, J.; Vishwanath, A.; Kalyanaraman, S.; Gort, A. PV generation and demand mismatch: Evaluating the potential of residential storage. In Proceedings of the 2015 IEEE Power \& Energy Society Innovative Smart Grid Technologies Conference (ISGT), Washington, DC, USA, 18-20 February 2015; pp. 1-5.

14. Horan, P.; Luther, M.B. How big should my battery be? In ASA 2018: Engaging Architectural Science: Meeting the Challenges of Higher Density, Proceedings of the 52th International Conference of the Architectural Science Association, Melbourne, Australia, 28 November-1 December 2018; Rajagopalan, P., Andamon, M.M., Eds.; Architectural Science Association: Melbourne, Australia, 2018; pp. 249-256. [CrossRef]

15. Tant, J.; Geth, F.; Six, D.; Tant, P.; Driesen, J. Multiobjective Battery Storage to Improve PV Integration in Residential Distribution Grids. IEEE Trans. Sustain. Energy 2013, 4, 182-191. [CrossRef] 
16. Forrest, K.E.; Tarroja, B.; Zhang, L.; Shaffer, B.; Samuelsen, S. Charging a renewable future: The impact of electric vehicle charging intelligence on energy storage requirements to meet renewable portfolio standards. J. Power Sources 2016, 336, 63-74. [CrossRef]

17. Sarabi, S.; Davigny, A.; Courtecuisse, V.; Riffonneau, Y.; Robyns, B. Potential of vehicle-to-grid ancillary services considering the uncertainties in plug-in electric vehicle availability and service/localization limitations in distribution grids. Appl. Energy 2016, 171, 523-540. [CrossRef]

18. Weniger, J.; Tjaden, T.; Quaschning, V. Sizing of Residential PV Battery Systems. Energy Procedia 2014, 46, 78-87. [CrossRef]

19. Aichhorn, M.; Greenleaf, M.; Li, H.; Zheng, J. A cost effective battery sizing strategy based on a detailed battery lifetime model and an economic energy management strategy. In Proceedings of the 2012 IEEE Power and Energy Society General Meeting, San Diego, CA, USA, 22-26 July 2012; pp. 1-8. [CrossRef]

20. Xiao, H.; Pei, W.; Yang, Y.; Kong, L. Sizing of battery energy storage for micro-grid considering optimal operation management. In Proceedings of the 2014 International Conference on Power System Technology, Chengdu, China, 20-22 October 2014; pp. 3162-3169. [CrossRef]

21. Muenzel, V.; De Hoog, J.; Brazil, M.; Vishwanath, A.; Kalyanaraman, S. A Multi-Factor Battery Cycle Life Prediction Methodology for Optimal Battery Management. In Proceedings of the 2015 ACM Sixth International Conference on Future Energy Systems ACM, Bangalore, India, 14-17 July 2015; pp. 57-66.

22. Calculate Solar Array Size and Cost. Available online: http://sroeco.com/solar/calculate-solar-cost/what_size_solar_system_ do_i_need/ (accessed on 11 August 2017).

23. Solar Calculator. Available online: https:/ / solarcalculator.com.au/ (accessed on 6 April 2020).

24. Agnew, S.; Dargusch, P. Effect of residential solar and storage on centralized electricity supply systems. Nat. Clim. Chang. 2015, 5, 315-318. [CrossRef]

25. Duffie, J.A.; Beckman, W.A. Solar Engineering of Thermal Processes, 2nd ed.; John Wiley \& Sons, Inc.: New York, NY, USA, 1991 ; p. 5.

26. NASA. Surface Meteorology and Solar Energy-Available Tables. Available online: https://eosweb.larc.nasa.gov/cgi-bin/sse/ sse.cgi?+s01 (accessed on 28 June 2016).

27. McKay, D. Sustainable Energy-Without the Hot Air, 1st ed.; UTI Cambridge Ltd.: Cambridge, UK, 2009 ; p. 39.

28. Department of the Environment, National Greenhouse Accounts Factors-2015; Department of the Environment, Commonwealth of Australia: Canberra, Australia, 2015; p. 18, ISSN: 2202-333X.

29. Department of the Environment, National Greenhouse Accounts Factors-2018; Department of the Environment, Commonwealth of Australia: Canberra, Australia, 2018; p. 19, ISSN: 2202-333X.

30. AEMO. Meter Data File Format Specification NEM12 and NEM13; Version 1.06, December 2017; Australian Energy Market Operator Ltd.: Melbourne, Australia. Available online: https://www.aemo.com.au/-/media/Files/Electricity/NEM/Retail_ and_Metering/Metering-Procedures/2018/MDFF-Specification-NEM12--NEM13-v106.pdf (accessed on 2 May 2021). 